\title{
But Is It Sociology?
}

\author{
MONICA J. CASPER \\ UNIVERSITY OF ARIZONA
}

\begin{abstract}
This essay explores issues of trandisciplinarity through an autobiographical lens. Specifically, the essay attends to tensions between the discipline of sociology and interdisciplinary science, knowledge, and technology studies, with an emphasis on differing epistemic cultures in each. The author suggests the promise of border-crossings outweighs the challenges, and advocates for a reflexive practice that names our intellectual and political commitments. Eschewing traditional notions of objectivity, the author calls for transdisciplinary and public engagement.
\end{abstract}

\section{Keywords}

animal studies, articulation work, boundary objects, Chicago School, critical body studies, disability studies, epistemic cultures, first-generation, medical sociology, objectivity, public sociology, reproduction, transdisciplinarity, trauma studies, women's health

\section{Openings}

A key lesson of science and technology studies is that knowledge is always situated (Haraway 1988). What we know, how we know it, our representations, and even the questions we ask at the outset are shaped by our structural locations (e.g., who and where we are in the world) and the social, cultural, political, and economic contexts of knowledge production. Classic work in our field has unfolded various "black boxes" to demonstrate how these objects of knowledge have come to be understood as truths. Intimate attention to knowledge production has meant that we have also examined producers of knowledge: scientists, clinicians, lab assistants, theorists, research animals, experimental models, molecules, funders, governments, NGOS, and the myriad tools that together have created what we know. STS stories have necessarily been biographicalwe have excavated people as often as we have unraveled ideas and facts. In that spirit, I offer this essay about my own career trajectory and knowledge production, including tensions between insights of STS and my home discipline, sociology.

' Monica Casper, email: mjcasper@email.arizona.edu

Copyright (C) 2016 (Monica Casper). Licensed under the Creative Commons Attribution Non-commercial No Derivatives (by-nc-nd). Available at estsjournal.org. 


\section{Origins}

1990 was a big year. U.S. troops invaded Iraq, initiating the (first) Persian Gulf War. Nelson Mandela was freed from prison after 27 years of confinement. Margaret Thatcher resigned as British Prime Minister. The Hubble Space Telescope was placed into orbit by Discovery and Senator Barbara Mikulski introduced the Women's Health Equity Act. Wilson Phillips, Sinead O'Connor, and Madonna all had hit songs, and the highest grossing film that year was Ghost. And the Science, Knowledge, and Technology (SKAT) Section of the American Sociological Association was born, an event well worth celebrating.

1990 is especially meaningful to me because it was also the year I drove from Chicago to San Francisco to commence graduate school at UC San Francisco. I was 23 years old, had graduated college two years earlier, and was eager to embark on women's health research with Adele Clarke and Virginia Olesen. But let me back up for a moment, as I'm describing the journey as more linear than it actually was.

I started college at the University of Chicago in 1988, a first-generation student intent on a career in law and policy. (I planned to be Chief Justice of the Supreme Court.) I majored in sociology, became interested in the history of medicine after taking a class on the professions with Edward Laumann, and eventually wrote a thesis on the transition in birth care from midwifery to obstetrics, with Laumann and Wendy Griswold supervising. Through my four years at Chicago, I discovered this thing called academia, a career trajectory not on my radar prior to college as the daughter of working-class parents.

Reading, writing, and talking to people for a living? I was hooked.

But I remained uncertain: law school or a Ph.D.? Which was most "legible" to me, to my family, to my earlier sense of self, and to the better world I wanted to create? I worked for two years in Chicago post-B.A., at the campus library and then as the development coordinator for a domestic violence shelter. I was also active in reproductive politics and was determined to center my professional efforts on women and reproduction (recall that the late 1980s saw the rise of the Religious Right). When I came across information about the UCSF doctoral program, with its robust emphasis on women's health, qualitative methods, and medical sociology, it felt like home--and that was before I had spoken to any of the faculty! I remember excitedly holding the brochure in my hands (this was pre-Internet) and phoning Adele Clarke on, yes, a landline. I asked if she was planning to stay at UCSF, somehow prescient that having the same advisor from start to finish was critical. She was indeed, so I leapt into the fray- and Adele, mentor and long since precious family member, has been in my corner from day one.

I studied medical sociology and women's health at UCSF, as planned, but I also discovered science and technology studies. Adele taught a course on STS/M (important to add the $\mathrm{M}$ for medicine), where we read everything from Ludwig Fleck and Thomas Kuhn to Bruno Latour and Steve Woolgar to Sandra Harding and Donna Haraway, and well beyond. I also worked as Adele's research assistant on projects including planning a biotechnology workshop, the Pap smear research that eventually became co-published articles and a section of Our Bodies, Ourselves, and helping to pull together The Right Tools for the Job (Clarke and Fujimura 1992)-as 
in, photographing images and laborious footnote checking, because again, this was all preInternet and I actually had to visit the library.

During graduate school, I was introduced to a number of other STS scholars including Donna Haraway, first through Primate Visions and later in person. Donna became the external member of my dissertation committee and later, a cherished colleague and mentor at UC Santa Cruz. Also during my time at UCSF, Leigh Star and Joan Fujimura were intellectual "aunties," both of them connecting me to their own students and networks, folks like Stefan Timmermans. My dear friend and longtime collaborator, Lisa Jean Moore, was part of this world, too, traveling through doctoral study with me and helping to shape my professional and personal trajectories. By 1995, when I completed the Ph.D., I was firmly and happily an STS person-of the feminist and biomedical persuasion.

And yet...

\section{Intersections}

Being an STS person has meant that for a quarter century, I-like many of my colleagues--have been negotiating my intellectual and professional relationships to the broader discipline of sociology. This has been exciting, fruitful, and also at times deeply vexing and tiresome. When I completed my B.A. thesis in 1988, Wendy Griswold remarked, "This is really smart, but I'm not sure it's sociology." I was less upset by her comment than one might think a 21-year old with class and gender insecurities would be; mostly, I took it as an invitation to think about-and to eventually travel back and forth across-the boundaries of a discipline that I love. A Chicago School sociologist in many senses of the term, I have attempted to approach my own career, including my commitments to SKAT specifically and to STS/M more broadly, in ecological, open-minded, pragmatic, and transdisciplinary fashion. It is not surprising, then, that I have forged a career both in and out of sociology, and both in and out of academia.

With the benefit of hindsight, it is clear to me that STS as a diverse intellectual space has offered both tacit and tangible permission to engage in transdisciplinary scholarly work while resculpting the edges of the discipline. Simultaneously, my graduate education under Adele's loving mentorship, while deeply grounded in sociology, offered the freedom to explore a variety of ideas, theories, methods, perspectives, and topics. This training was both professionally centered and intellectually unbounded. Science and technology studies-- my first transdisciplinary foray beyond women's studies-- taught me to be theoretically and methodologically versatile. I learned to "follow the molecule" and not necessarily the rules. When you study molecules--or fetuses, chemical weapons, cervical cancer, the HPV vaccine, and infant mortality-- you learn to snake through bodies, sneak across borders, and question the institutional status quo, including hegemonic representations. This kind of empirical flexibility is not always legitimate in sociology, where borders and boundaries are more heavily policed. (An example: during a job interview many years ago, I was asked about my first book, "But how is this sociology?" That book later won the C. Wright Mills Award.) 
Since the early days of my career, I have tentacled into many other interdisciplinary spaces, yet have always carried the insights of STS/M with me. My research encompasses-- and has helped to cultivate - critical studies of the body, disability studies, and critical trauma studies, to name a few. Recently, I have crept gingerly into animal studies, arriving there via trauma studies and an investigation of catastrophic harm to elephants. While I certainly want to pose and answer questions germane to each area in which I work--questions that are fundamentally about social processes - what draws me to these fields is not "disciplinary" inquiry per se, but rather social stories, problems, and possibilities for change.

Now at the midpoint of my career, I have come to realize that much of my work for the past quarter century has been about engaging three big questions: First, conjuring Max Weber, who was interpreting Leo Tolstoy: how shall we live? Second, invoking Michel Foucault: who do we let die? And third, echoing feminist scholars everywhere: where are the women?

These questions, though sociological, are not limited to sociology alone. Indeed, they encourage me, and perhaps us, to think through how science, knowledge, and technology studies fit into sociology and into wider transdisciplinary endeavors. The thing is, SKAT has never been just the sociology of science, or the sociology of technology, or the sociology of knowledge. It has been all of these simultaneously, and more. Unlike many sections in the American Sociological Association, it centers not the discipline itself ("sociology of"), but rather a particular kind of approach, an assemblage of stances toward, an opening, a set of questions. Drawing sustenance both from within the discipline and from the capacious domain of STS/M, the section has attended to the ways we make and remake the world, and it has done so for the most part reflexively. It is one of the few places in sociology that I have found to be receptive to examining its own epistemological maneuvers and the profound consequences of the knowledge we, and others, produce.

Transdisciplinary work, it seems to me, presents both constraint and opportunity as epistemic cultures collide. When we make ourselves into "boundary objects" (Star and Griesemer 1989) that travel between our home discipline and wider STS / M (and other) intellectual worlds, we engage in the work of articulation, as Anselm Strauss (1988) called it, as well as translation. We bring important transdisciplinary perspectives to the discipline, hoping to blur the edges, while also bringing sociological rigor and longstanding concerns about social processes, power, and people to transdisciplinary spaces. And we articulate and translate these concerns through our own embodied labor, through our migrations to and fro, and through the very real work of trying to grasp the projects of other disciplines we engage.

Opportunities emerge from magnification and expansion of the kinds of questions we can ask when we push past our disciplinary boundaries, when we engage other "ways of seeing" (Berger 1973). And yet there are constraints, too: articulation work is hard, and who among us has not been bruised from bumping up against the solid wall of epistemological and methodological certainty that permeates our home discipline? Too many times we are told, "This isn't sociology." But STS/M, and its kindred transdisciplinary endeavors, engages in crucial intellectual and political work when we say, "Yes, this is sociology, too. Come join us." 


\section{Provocations}

Let me end this essay with some thoughts on what it means to engage in the public sphere, surely an issue related to what counts as sociology and science and technology studies. There is still considerable suspicion in sociology regarding "normative" intellectual work; those of us who traffic in politics, who cross the great divide between academia and everything else, are viewed as having "an agenda." So I will be explicit here: I do have an agenda. So do we all. And STS, among other enterprises, taught me many years ago that our work can never be disentangled from the contexts of its production.

This contemporary moment is remarkably fraught for STS/M scholars; I often find myself in the odd position of defending science against its detractors. Whether the issue is women's health, climate change, or health disparities, science and its public representations matter. Often a great deal, as these are matters of life, death, and planetary survival. In recent years, as I have begun to engage more publicly through The Feminist Wire and other spaces, I have come to realize that I am not necessarily speaking for science as an objective practice, but I am speaking against ignorance and the conditions that produce it. These conversations are difficult, for they require nuance and complexity in a shallow Twitter zeitgeist. But if we do not engage, who will?

This leads me to longstanding questions of objectivity and participation in the public sphere. In some sociological circles, we are told that non-objectivity is unwelcome partiality, not scientific, and untrustworthy. To be partial is to produce a kind of sociological fiction, to be a dishonest fabricator. Debates about objectivity are about more than the quantitative / qualitative split, as they are often framed; rather, they speak to the heart of our collective ontology and the kinds of scholars we claim and desire to be. STS/M folks have entered these debates along various intersecting pathways, traveling through strong objectivity, standpoint epistemology, situated knowledges, new (or not so new) materialisms, and more. In doing so, we have challenged and occasionally-- but not always- dissolved rigid disciplinary boundaries.

In closing, I invite you to share in engaging complex questions of objectivity and our diverse socio-affective-intellectual investments in the world. I also invite you to consider breaching the seemingly obdurate but surprisingly porous barrier that separates academia from everything else. My quarter century of scholarship has taken to heart Howard Becker's (1967) claim that sociologists are always looking over somebody's shoulder, trying to see from their vantage point, always somehow committed. So I will end with both a declaration and a provocation: As a woman of a certain age, a mother of girls, a daughter of the laboring class, a participant in racial justice movements, an embodied being, and an inhabitant of our imperiled planet, I simply cannot afford what too often passes for objectivity. Instead, I try to articulate my commitments clearly, and I invite you to do so, too.

\section{References}

Becker, H. 1967. “Whose Side Are We On?” Social Problems 14 (3): 239-247.

Berger, J. 1973. Ways of Seeing. British Broadcasting Corporation and Penguin Books. 
Clarke, A. E. and Joan H. Fujimura, eds. 1992. The Right Tools for the Job: At Work in TwentiethCentury Life Sciences. Princeton: Princeton University Press.

Haraway, D. 1988. "Situated Knowledges: The Science Question in Feminism and the Privilege of Partial Perspective." Feminist Studies 14 (3): 575-599.

Star, S. L. and J. Griesemer. 1989. "Institutional Ecology, 'Translations' and Boundary Objects: Amateurs and Professionals in Berkeley's Museum of Vertebrate Zoology, 1907-39." Social Studies of Science 19 (3): 387-420.

Strauss, A. 1988. "The Articulation of Project Work: An Organizational Process." The Sociological Quarterly 29 (2): 163-178. 